\title{
Curriculum Construction and Reform Practice about Post-press Processing Principle and Process
}

\author{
Bo Gao \\ Department of Printing Engineering, Beijing Institute of Graphic Communication, Beijing, China \\ gaobozx@163.com
}

Keywords: Printing engineering, Teaching mode and method, Experimental teaching.

\begin{abstract}
With the development of printing engineering, the needs of the construction and development of the course has made it in an important position for Post-press Processing Principle and Process in the process of talent cultivation. Post-press Processing Principle and Process is an important professional printing engineering core courses, including basic content such as the post-press processing technology, materials and equipment. This paper mainly carried on the exploration and practice effectively on the adjustment and integration of curriculum structure, curriculum content, the integrated application of suitable teaching mode and teaching method, renew the idea of experimental teaching, strengthening practice teaching link and so on.
\end{abstract}

\section{Introduction}

In recent years, according to the requirements of construction of the school and the development of the discipline, the development of printing engineering has made it in an important position for Post-press Processing Principle and Process in the process of talent cultivation. Post-press Processing Principle and Process is an important professional printing engineering core courses, and it plays an important role in the process of training senior engineering and technical talents. It is the collection of manufacturability and practical, with major difference among other professional courses, including basic content such as the post-press processing technology, materials and equipment [1].

Specific teaching contents include the post-press processing technology, materials, equipment and basic knowledge, theory and skills that is involved. The knowledge of covering field is widely, holding the characteristics of various types of knowledge. It requests both on the theory of knowledge and a grasp of the practical operation skills. Therefor it is a quality education in engineering courses.

During the study of this course, students could have a basic understanding of the process of post-press, be familiar all kinds of methods and principal of process, understand the corresponding processing equipment. It also could cultivate students' ability to analyze and solve problems, to strengthen the cultivation of practice ability and innovative thinking ability. It will lay the necessary quality foundation and necessary basis for engineering applications be the future work.

In the teaching process, how to adjust and integrate the course curriculum structure and content to make it easier for students to get the teaching content, how to apply the right teaching mode and teaching method to make it major for students' understanding and improve the students' practical ability and engineering practice ability is the research emphasis. This paper discussed and summarized on curriculum structure, teaching content, teaching mode and teaching method reform of experiment teaching and so on.

\section{Reasonable optimization and integration of teaching content}

Post-press Processing Principle and Process is a comprehensive and practical course collected of the post-press processing technology, materials and equipment. This paper discussed about how to effectively accomplish the teaching contents in class, make students get a better understand and master the knowledge and to better achieve the teaching goal. First of all, we should get a reasonable optimization and integration of teaching content. 
When we explain the implementation process of all kinds of printing products, we put the main lain in the print products processing and principle, gradually introduced main technical contents of printing products post-press processing as a comprehensive system, step by step, and selectively introduced the relevant processed materials involved in the type, performance and applied to the basic content of related equipment. We distributed the teaching content for the reasonable allocation, to make the course content clear, more facilitate for students to understand and grasp.

At the same time, we introduced new technology, new material, new equipment, etc.in post-press processing technology. Such as magnetic cutting, hologram, screen printing refraction and other new technology, and such as new materials polyurethane adhesives, compound pre-coating film without glue, especially the new development in post-press processing equipment, automatic line technology, etc. Students could fully understand the technology development present situation, so as to adapt to the needs of the industry.

According to different teaching contents and characteristics, we also hired engineering technology personnel to give lectures, who combined with the enterprise actual to introduce some engineering knowledge, new technology, new development trend and the latest progress of foreign knowledge. It made students feel more close to the actual, close to life, and gave an increase for the enthusiasm of students. The reflection is good.

\section{Pay attention to the study and practice of teaching mode and teaching method}

Under the guidance of teaching concept of making the students the core, in combination with giving knowledge, training ability, quality education, teachers for this course attach great importance to the teaching mode, teaching method and teaching means and application, try to change from "giving them fish" to "teaching them to fish". We attach importance to both the leading role that teachers play, and also to respect the principal position of students in teaching learning activities. We actively advocate the heuristic teaching, arising the enthusiasm and initiative of student learning, guiding students to active thinking.

During the teaching, we use the "heuristic", "analysis of contrast" and other teaching methods, to improve the enthusiasm and initiative of students in learning, and form a discussion-based teaching mode. We pay attention to ability training, focus on strengthening the foundation, broadening the knowledge and vision, increasing students' interests. Teachers for this course are able to constantly introduce some engineering examples, such as using the non-plastic coated products and stereo bronzing products, to expand students' vision and increase students' knowledge, to make the content of the course always stay strongly advancement (pick up the popular hologram products). This can not only improve the students' interest in learning, also can open up their world, which has obtained the good teaching effect [2 3].

At the same time, we put attention on case study, for it is an effective way to improve the students' ability training. During the teaching, using the case study, we must closely combines the actual conditions of post-press processing technology, using the perfect typical teaching case, to show the post-press processing various technical link in actual operation. The case has the characteristics of objective reality, truthful and accurate, so it could guide students to understand and analyze, and to explore the method to solve the problem, to improve students discover problems, analyze and solve problems.

In the teaching book binding process, we could take typical wireless glue paperback book as an example, combining the reality of the development of the wireless gum. According to the equipment function it can be divided into single machine production and the production of production line. According to the different bonding material, its manufacturability also can be different. Through this case to show each link in actual operation process for the post-press processing, makes the students to get an objective, authentic, accurate understanding of the paperback wireless glue order process and production process.

By the actual cases such as folding the propaganda color pages, hot stamping film, the structure of the hardcover book, we analysis of its technology, materials and equipment, making the class lively and interesting. Paying attention to the participation of the students and cultivate the practical ability, organize students to practice in class, homework extracurricular handmade, to raise the ability of students. Figure 1 is a student of handmade pictures. 


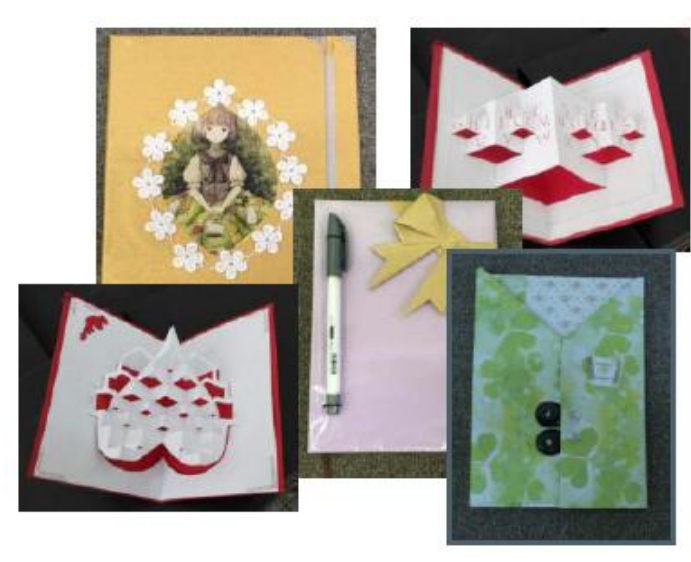

Fig.1 Handmade pictures of students

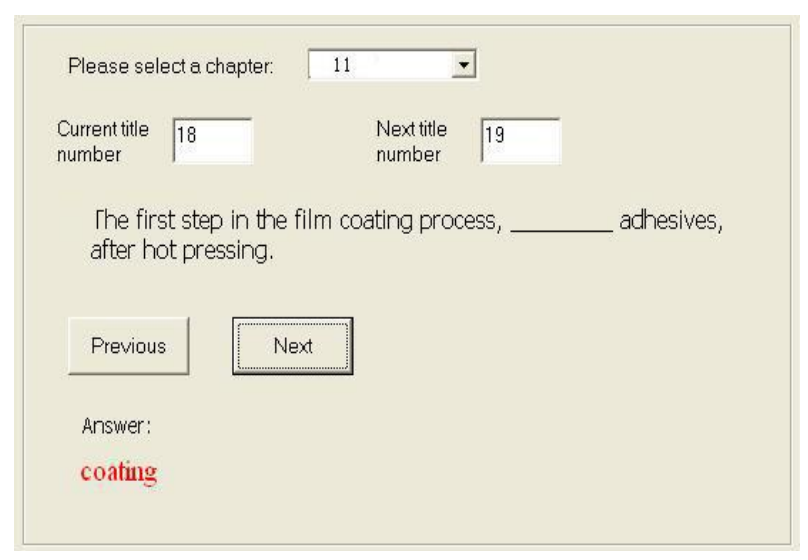

Fig.2 Self-test assisted exercises

In the teaching, we also pay attention to the use of modern media technology, such as computer technology to develop the test training system as shown as figure 2, to facilitate the relevant teaching. It has a certain effect for students to understand and grasp the hardcover book cover design. In the teaching of "folding" technology, there are many kinds of folding form. If we only use general teaching or pictures show, because of students' lack of perceptual knowledge in folding, the result is bad. Using dynamic display can solve this problem well. In figure 3, by folding form the dynamic features and application in the folding machine, causes the student to obtain certain perceptual knowledge, deepen students' understanding of the related content [4].

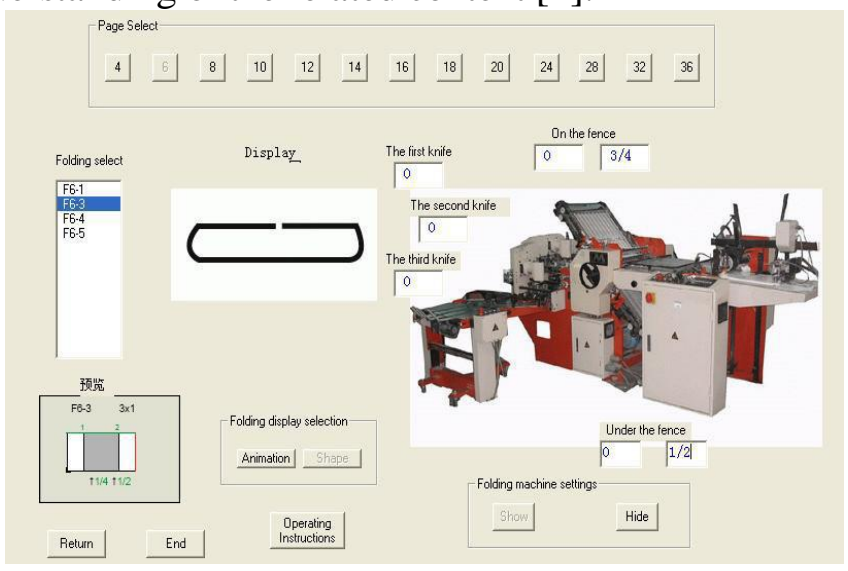

Fig.3 Folding principle of auxiliary exercises

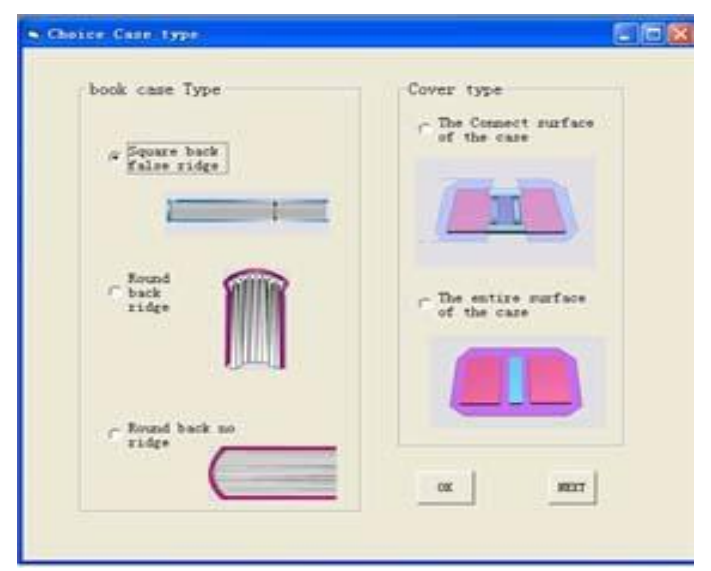

Fig.4 Hardcover design interface

\section{Update the practice teaching idea and pattern}

In the practice teaching, update the teaching idea and improve the teaching effect. Using our expertise to actively develop the experimental teaching design software platform, as shown as figure 4, realize the interactive teaching, demonstration teaching method, to make the students get training simulation of the production practice. By experiment design, we can guide students through experimental observation, thinking to find the problem, active their learning atmosphere, open their field of vision, to give full play to the potential ability of students, inspire the students more creative ability and innovative consciousness.

We encourage students to take an active part in extracurricular activities of science and technology at the same time. Through the teachers and students attending college study plan to further improve the scientific research activities of practical engineering ability, cultivate team spirit of cooperation. Students take part in extra-curricular activities completed by the students of science and technology research projects: animation design and production of the principle of several kinds of coating for school won third prize of science. Students used 3dmax to build models and produced several kinds of commonly used coating and principle of animation. The animation has stereo effect, and can more vividly demonstrate the process of coating. It contributes to the intuitive teaching, to make students easier to understand. In the 
process, it can both deepened students' understanding of the principle of coating and process, also improved the students' practical ability, which has received the good effect.

According to the teaching content, we developed multiple project of experiment teaching. Some experiment virtual experiment platform is developed, which makes students cannot be restricted by time and space, and gets interest of the students. The experimental effect is good.

\section{Summary}

After years of exploration and practice, we have constructed a reasonable curriculum system, formed the perfect teaching content, and finished a series of teaching achievements in the innovation of teaching mode, teaching method and practice teaching link. We are still in application, improvement and perfect continuously in the teaching practice, to make nearly 5 sessions of printing engineering students benefit in different degrees. For now, we have got a good reflection of students and achieved a high evaluation. It has kept the teaching effect and teaching quality improved obviously.

\section{Acknowledgement}

The production of this paper is funded by projects on teaching reform of Beijing Institute of Graphic Communication on principles and finishing processes teaching model reform and research and by 2015Undergraduate training of Personnel training mode innovative pilot project Bisheng excellent engineer class (No.03150115004/002) .

\section{References}

[1] Gao Bo, Wang Wei Min: Science and Technology Innovation Herald, No.1 (2010), p.100.

[2] Zhang Xiaogui and Gao Bo: Heilongjiang Researches on Higher Education, Vol.8 (2006), p.117.

[3] Gao Bo, Wang Yu: China Printing and Packaging Study, Vol.02, No.4 (2010), p.54.

[4] GAO Bo, ZHAO Zhiqiang, WANG Weimin: Advanced Materials Research, Vols. 591-593 (2012), p.2254. 